posts are required for clinical academic staff who wish to devote most of their time to research.

(17) Similarly, 100 career posts are needed for basic scientists working in clinical research groups.

(18) Funds are required for establishing approximately 50 combined $\mathrm{MB}$ and $\mathrm{PhD}$ programmes and for restoring adequate public financing of a sufficient number of intercalated BSc degree courses to its previous level.

(19) The NHS must take a much greater part in the support of research and development.

(20) Basic clinical teaching will continue to require attachment of students to a substantial number of inpatients. At this early stage it is important to ensure that this attachment can take place in the main teaching hospitals.

(21) The NHS must be persuaded of the need for much better teaching facilities on its premises.

(22) The erosion of staff time for both teaching and research caused by the implementation of Achieving $a$ Balance must be stopped and corrected.

(23) There should be better representation of academic medicine on the Central Manpower Committee.

(24) Better mechanisms should be found for ensuring that academic needs are considered fully when staff are allocated within health regions.

(25) The higher specialist training committees should be asked to make their requirements for accreditation more flexible so that future clinical academics are not constrained to a relatively few rigid training programmes.

(26) Parity of salaries with NHS colleagues must be maintained for clinical academic staff and their removal expenses should be provided.
Members of the group are as follows:

Sir Raymond Hoffenberg, (chairman), president, Royal College of Physicians; Mr L D Abrams, University Hospitals Association; Dr P A J Ball, consultant physician; Sir Christopher Booth, president, Royal Society of Medicine; Professor A J Buller, Muscular Dystrophy Group of Great Britain; The late Professor C G Clark, former professor of surgery at University College Hospital; Dame Barbara Clayton, honorary research fellow in metabolism, University of Southampton; Professor R D Cohen, professor of medicine, The London Hospital Medical College; Miss Barbara Crispin, assistant secretary, Committee of Vice Chancellors and Principals; Professor C J Dickinson, professor of medicine, St Bartholomew's Medical College; Professor Sir Colin Dollery, director, Department of Medicine, Royal Postgraduate Medical School; Dr D C Evered, second secretary, Medical Research Council; Professor T W Glenister, dean, Charing Cross and Westminster Medical School; Professor G S Kilpatrick, vice provost, University of Wales College of Medicine; Dr J G G Ledingham, May reader in medicine, University of Oxford; Professor N McIntyre, professor of medicine, Royal Free Hospital School of Medicine; Professor G P McNicol, Committee of Vice Chancellors and Principals; Professor M F Oliver, Duke of Edinburgh professor of cardiology, University of Edinburgh; Professor M J Peckham, director, British Postgraduate Medical Federation; Professor D K Peters, regius professor of physic, University of Cambridge; Dr D A Pyke, registrar, Royal College of Physicians; Professor J P Quilliam, former chairman, Medical Academic Staff Committee of BMA; Dr C J C Roberts, former chairman, Standing Committee of Members, Royal College of Physicians; Professor D A Shaw, dean of medicine, University of Newcastle upon Tyne; Sir Maurice Shock, former chairman of the Committee of Vice Chancellors and Principals, rector of Lincoln College, Oxford; Dr C L Smith, British Medical Association; Professor J D Swales, chairman, Federation of Associations of Clinical Professors; Professor Sir David Weatherall, Nuffield Department of Clinical Medicine, John Radcliffe Hospital, Oxford; Sir David Innes Williams, chairman of council, Imperial Cancer Research Fund; Professor J D Williams, professor of medical microbiology, The London Hospital Medical College; Dr P O Williams, director, Wellcome Trust.

\title{
Obstacles to acceptance of clinical decision analysis
}

\author{
J I Balla, A S Elstein, Caryn Christensen
}

Postgraduate Medical Education Unit, University of Hong Kong, Hong Kong J I Balla, FRACP, professor

Department of Medical Education, University of Illinois, Chicago, USA A S Elstein, PHD, professor Caryn Christensen, PHD, assistant professor

BrMed f 1989;298:579-82
Clinicians work in an environment characterised by uncertainty and, for the most part, use intuitive methods to make choices between strategies in diagnosis and management. It comes as no surprise that they are not always successful in their choices and improvements should be looked for and welcomed. One approach would be to attempt to develop a prescriptive theory of clinical work with its accompanying techniques. ${ }^{1} \mathrm{~A}$ formal method for decision making should take into account the likelihood of the outcomes of actions, the risks and benefits associated with these outcomes, and value judgments on how the patient's interests are best to be served. ${ }^{2}$ The theory should make it possible to generalise from clinical experience and allow a systematic examination of the actions of clinicians within its framework. ${ }^{1}$

\section{Three building blocks}

Clinical decision analysis is assembled from three simple building blocks, though in application these may be complex.

Firstly, $2 \times 2$ tables help us visualise the statistical properties of test results. Sensitivity (true positive rate) and specificity (true negative rate) can be presented in such tables - for example, how often are computed tomograms abnormal in the presence or absence of brain tumour?

Secondly, Bayes's theorem allows the calculation of: (a) the probability of the presence of a condition given certain clinical findings, and $(b)$ the revision of probabilities associated with any given test result. For example, Bayes's theorem allows the estimation of the probability of acute appendicitis being present when there is pain in the right iliac fossa, associated with tenderness and guarding in a 21 year old woman. Or it allows us to assess what diagnostic importance in probability terms should be attached to a normal computed tomogram in a patient with headache.

Thirdly, decision trees give an explicit pictorial representation of alternative strategies. They can also incorporate probabilities and utility assessments into the options available to the decision maker. For example, a decision tree can be used to help answer the question: What is the best treatment to recommend to a patient suffering from transient ischaemic attacks in terms of the risks of the condition and those of treatment by medical or surgical means? 


\section{$2 \times 2$ Table}

\begin{tabular}{lccc}
\hline & Disease & No disease & Total \\
\hline $\begin{array}{l}\text { Test positive } \\
\text { Test negative }\end{array}$ & $\begin{array}{c}\text { True positive } \\
\text { False negative }\end{array}$ & $\begin{array}{l}\text { False positive } \\
\text { True negative }\end{array}$ & $\begin{array}{c}\text { Total positive } \\
\text { Total negative }\end{array}$ \\
\hline & Total disease & Total no disease & Total cases
\end{tabular}

Basic structure of $2 \times 2$ tables showing all possible test results in relation to presence or absence of disease

\begin{tabular}{lccr}
\hline & $\begin{array}{c}\text { Headache due } \\
\text { to tumour }\end{array}$ & Other headache & Total \\
\hline CT positive & 1 & 10 & 11 \\
CT negative & 0 & 989 & 989 \\
\hline & 1 & 999 & 1000 \\
\hline
\end{tabular}

Results of computed tomography (CT) in 1000 hypothetical cases of unselected headache given that the prior probability of tumour was $1 / 1000$, the true positive rate of computed tomograms for tumour was 0.96 and the false positive rate 0.01 .

Given that these building blocks are available and can be combined and that there are many successful examples of their use, it would be reasonable to expect that clinicians would be interested in any manoeuvres by which they could address the problems posed by complex tests and new technology. This is not the case, however. These techniques have had little effect on the way clinical decisions are reached and attempts to teach clinical decision analysis to undergraduates meet with resistance. ${ }^{3}$ We examine here why clinical decision analysis is needed and why it is slow to achieve acceptance.

\section{Why is clinical decision analysis needed?}

We can distinguish between the need for clinical decision analysis based, on the one hand, on inadequacies and complexities in information and, on the other hand, on the intrinsic qualities of the clinician.

\section{INADEQUACIES AND COMPLEXITIES OF INFORMATION}

Incomplete or imperfect data-Certainty is rarely achieved in medicine and therefore clinicians often have to make decisions when data are incomplete. Not only can Bayes's theorem be used directly to indicate probabilities but sensitivity analysis ${ }^{24}$ can also be used to show which information is essential and which can be ignored for rational decision making. For instance, we may have incomplete knowledge about the false positive rate of a test. In that case, by using Bayes's equation and a plausible range of figures for the false positive rate, we might be able to show that a decision reached based on the outcome of the test is insensitive to the exact value of the false positive rate and we can confidently make choices in the absence of such exact values. The converse may also be shown to be true.

Proliferation of tests - More and more tests constantly become available and all indications are that this will continue. When a new test is introduced there are no rules to say what place it has in a diagnostic sequence and the clinician needs aids to its interpretation. In addition, costs and potential morbidity need be considered along with the straightforward medical help that a new test may give. There are now several examples where clinical decision analysis has been helpful in developing well defined indications for the use of new tests. They include the use of computed tomography in head injuries ${ }^{s}$; the modern investigation of multiple sclerosis ${ }^{6}$; and the use of thallium in stress testing for angina.

The use of complex technology-Increasingly complex technology is applied in the care of patients, as in coronary care or intensive care units. With the aid of computers, algorithms have been developed and several such units are now aided by decision making that depends on the rational interpretation of the data obtained from the patient. ${ }^{8}$ Similarly, new methods of treatment can be evaluated and compared with traditional methods in the management of a number of conditions-for instance, the cost effectiveness of surgery versus angioplasty for renal vascularisation. ${ }^{9}$

\section{PROBLEMS WITH PROCESSING CLINICAL INFORMATION}

Difficulties in interpreting the statistical properties of data

In everyday clinical practice clinicians must carry approximate numerical or intuitive information in their heads. Doctors seem to have difficulty in achieving this even when relatively precise numbers are available. For example, to interpret clinical findings or laboratory data the true positive and true negative rates of the data must be known. This knowledge can then be combined with an assessment of prior probabilities. The true positive rates are frequently available but true negative rates are rarely known because most epidemiological observations are derived from diseased populations. ${ }^{10}$

\section{Common biases}

Many studies have shown systematic biases among expert and novice clinicians alike." The evidence suggests that the forms of bias seen are generalisable to most human behaviour which involves decision making and that they are not peculiar to the medical world. We give a few examples.

Base rate errors-Base rate assessments vary according to individual experience. For instance, in a study of gastroenterologists and surgeons base rate estimates for common diseases varied widely and were affected by the specialty. ${ }^{12}$ Surgeons tended to diagnose jaundice as being due to gall stones, while physicians would think of it in terms of infection or a drug reaction. Each practitioner overestimates the probability of the occurrence of the conditions he or she most frequently sees and treats.

Representativeness-When presented with yellow cerebrospinal fluid obtained at a lumbar puncture in a patient with headache a clinician may diagnose subarachnoid haemorrhage even in the absence of an accurate history of abrupt onset of symptoms. The decision maker thinks primarily of yellow fluid as equivalent to the presence of blood, though less commonly it could also be related to raised protein concentrations due to other causes, such as tuberculous meningitis. Judgment is made by perceived likeness to something well known to the decision maker even if the basis for this is otherwise wrong. ${ }^{13}$ In this instance the lack of the abrupt onset headache and the knowledge that tuberculous meningitis is common in the locality would indicate that a subarachnoid bleed would be a less likely diagnosis.

Availability - A diagnosis is made on what is most easily brought to mind, which in turn could be what has been most frequently and recently seen or has outstanding characteristics. ${ }^{14}$ In a study where students were given patients presenting with clinical pictures resembling about equally either asthma or cardiac disease most of them seemed to use this approach, referring to the most recently seen patients, rather than to frequency tables. ${ }^{15}$

Anchoring-Once an initial judgment is formed clinicians tend to ignore or give insufficient weight to other information..$^{13}$ In one study where early diagnostic cues given to subjects suggested cardiac syncope further information indicated that there was no change 
in cardiac rhythm while the patient was monitored during one of the syncopal episodes. ${ }^{16}$ Most experts ignored this later information and retained their initial diagnosis.

Framing of problems-Minor variations in the wording of a problem may exert major effects on the choices made, in clear violation of the principle that decisions ought not to vary over inconsequential changes in setting. ${ }^{17}$ The effect appears to depend on whether a particular outcome is viewed as a gain or a loss from a fixed point of reference. For example, preferences for surgery or radiation as the initial treatment for lung cancer were strongly affected by framing the outcomes as survival or mortality. ${ }^{18}$

\section{Obstacles to the acceptance of clinical decision analysis}

Many of the postulates of the theory behind clinical decision analysis are counterintuitive to the clinician. Furthermore, Pauker and Kassirer noted that many clinical decisions involve routine choices among "tried and true" alternatives. ${ }^{4}$ These do not require special contemplation or complicated mathematical techniques. Diagnoses can often be made on the basis of common "epidemiological" knowledge. An elderly patient who develops weakness on one side will almost certainly have had a stroke and, beyond an understanding of the patient's circumstances, neither much knowledge nor complex inference is needed to avoid diagnostic error. In consequence, confidence in the ability to diagnose will be high and it will appear unnecessary to use complex logical or statistical diagnostic aids. Similar considerations apply to a viral illness, when knowledge of what is happening in the community will usually lead to a working diagnosis; great diagnostic precision is again unnecessary in that most patients will get better anyway, and it simply is not worthwhile investing in further investigations to identify the virus. The fact that some illnesses will indeed be caused by a virus while others will not is rightly seen as being without importance.

Resistance to objective methods of diagnosis is also seen in relation to clinical syndromes which are generally defined by historical data-for example, anxiety state, migraine, and irritable bowel syndrome. Such "I say so" diagnoses 19 depend on the definition of experts. Though the criteria used to make the diagnosis are often open to debate, personal opinion remains fixed. It is thus difficult to convince experts that more rational and precise diagnostic methods are required, particularly if the outcome is favourable with existing methods, when precision may appear to be only marginally useful.

Another reason for the slow acceptance of objective diagnostic techniques is that data collected by history or physical examination or by the use of a test are treated as essentially perfect so that uncertainties, which are capable of being handled by statistical techniques, can be ignored..$^{20}$ Clinicians are also

\section{Bayes's theorem}

$\mathbf{P}($ Disease/test $)=\frac{\text { True positive rate of test } \times P \text { disease }}{\text { Trueposiciverateof }}$

True positive rate of test $\times$ Pdisease + false positive rate of test $\times$ P no disease test result

$$
\mathrm{P}(\text { tumour/abnormal CT })=\frac{0.96 \times 0.001}{0.96 \times 0.001+0.01 \times 0.999}=0.088
$$

Results of Bayes's analysis for abnormal computed tomogram (CT) for suspected cerebral tumour using the same data as in the example for $2 \times 2$ tables

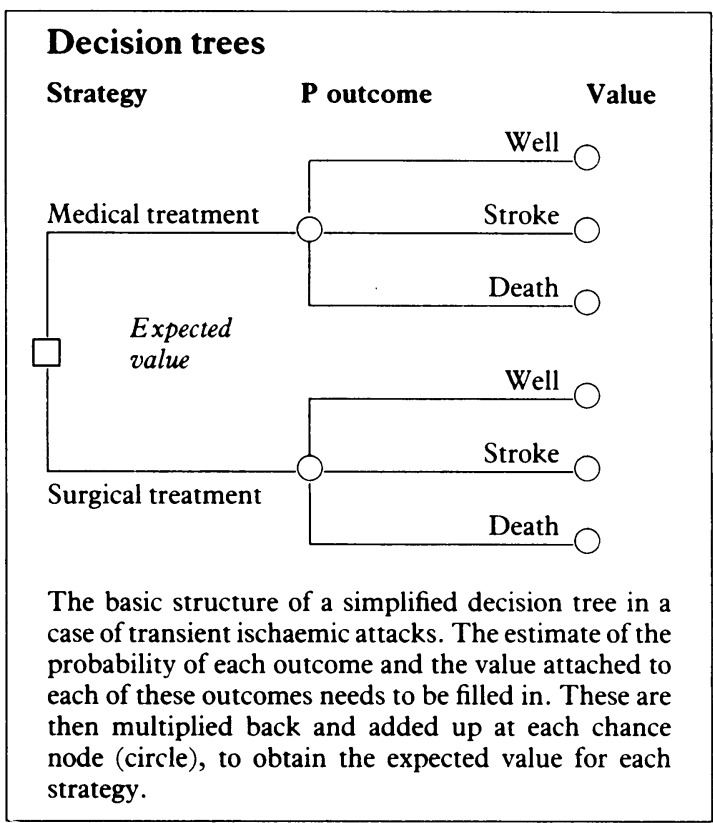

reluctant to use probability based estimates even though they are intuitively aware that diagnosis and management are based on such terms as "very likely" or "not very likely," which they tend to prefer to precise statements such as "with a probability of 0.95 or 0.005." Even when accurate estimates are made available, they find it difficult to appreciate their meaning and incorporate them into their decisions. ${ }^{21}$ Furthermore, the psychological importance of a particular probability biases the objective value accepted into a decision theory approach..$^{22}$ In clinical decision making very small probabilities are overweighted, so that rare events loom larger psychologically than they will in a decision analysis of the problem. ${ }^{17}$ Consequently, decision analysis can lead to results which, though consistent with the information supplied and with the rules of combining various estimates, "feel wrong" psychologically. A further stumbling block is that doctors tend to use psychological perceptions of risk which relate not only to actual or subjective probabilities but also to such matters as voluntary or involuntary exposure, fear, and newness or familiarity. These other aspects of risk are not expressed in a conventional probability, although they may be salient in clinical situations. Thus, when clinicians say that they cannot express their views about the riskiness of an intervention using probability scales, they may be referring to these other perceived aspects which in an objective analysis should be ignored. For example, it should make no difference in the consideration of a probability whether one is voluntarily or involuntarily exposed to a particular risk of death. Yet the clinician's concern about obtaining informed consent from patients shows that the distinction between voluntary and involuntary exposure to a risk for the sake of an anticipated benefit is psychologically quite meaningful. The fact that objective probability estimates are often not psychologically satisfying may lead clinicians to abandon their use.

Finally in our list of objections raised by clinicians to the use of clinical decision analysis is the idea of "utility." Some sort of utility function, determined by either the decision maker or the patient, or both, is implicit in every medical decision, but doctors nevertheless feel uncomfortable when asked to attach numerical values to outcomes. To equate death with zero and amputation or hemiplegia with 0.3 or 0.4 appears to be an overprecise way of measuring something which may well be immeasurable. Indeed these 
methods of assessment are too crude to have appeal and it is recognised that improvements are needed. We know that the theory of expected utility does not make allowance for the framing effect or for the psychological factors we have discussed (these are better described by prospect theory ${ }^{23}$ ).

\section{Future scenarios}

What then may we expect in the future? With advances in technology, and particularly organ imaging, the number of falsifiable diagnoses will increase. These tests will become cheaper and easily accessible. As a result of performing more tests, clinicians will become more aware of the diagnostic and management errors they make when using either simple "I say so" or "probabilistic" methods. At the same time, since the tests are performed looking for diseases with low base rates, they will need to worry more about the interpretation of a positive test result and may have difficulty in explaining their findings, owing to their lack of appreciation of the effect of base rates and the overpowering effect of the number of false positive results when testing for diseases whose base rates are low.

We conclude that present day decision theory can tell us a great deal about what is wrong with clinical decision making, but it is not always suitable for incorporation into the everyday work of the clinician. Decision theory can tell us what data are needed and how to interpret the results of tests. It can also help us make our utility assessment explicit. Once clinicians are made aware of these, however, they come to realise that many of their decisions must be made in the absence of sufficient information on many aspects of the data and of the outcomes. The condition thus becomes ambiguous rather than uncertain. ${ }^{24-26}$ This may be the direction for future theories of clinical work to take, by examining the basic tenets of ambiguity theory to see how they measure up to the realities of clinical life. Until then, however, we should take advantage of the many insights gained from our studies of clinical work within the decision analytic framework. We are not suggesting that it is either feasible or necessary to apply decision analytical methods to every clinical situation. Yet the insights into decision pro- cesses provided by the theory and the recognition of discrepancies between clinical intuition and formal theories should become part of the background and understanding of every clinician.

1 Dudley HAF. Axioms in clinical practice and their potential usefulness in education. Med Educ 1982;16:308-13.

Weinstein MC, Fineberg HV. Clinical Decision Analysis. Philadelphia: WB Saunders, 1985 .

3 Balla JI, Edwards HM. Some problems in teaching clinical decision making. Med Educ 1986;20:487-91.

4 Pauker SG, Kassirer JP. Decision Analysis. N Engl f Med 1987;316:250-8.

5 Balla JI, Elstein AS. Skull $x$ ray assessment of head injuries: a decision analytic approach. Methods Inf Med 1984;23:135-8.

6 Iansek R, Balla JI. A decision analytic approach to the role of VER and CSF in the management of singular spinal sclerosis. Clin Exp Neurol 1985;21: 49-5

7 Ong YS, Quaife MA, Dzindzio BS, et al. Clinical decision-making with treadmill testing and thallium 201. Am f Med 1980;69:31-8.

8 Norton LW, Eiseman B. Surgical decision making. 2nd ed. Philadelphia: WB Saunders, 1986.

9 England WL, Roberts SD, Grim CE. Surgery or angioplasty for cost-effective renal revascularization. Med Decis Making 1987;7:84-91.

10 Sackett DL. Clinical epidemiology: a basic science for clinical medicine. Boston: Little, Brown, 1985.

11 Dawson NV, Arkes HR. Systematic errors in medical decision making: judgment limitations. $\mathcal{F}$ Gen Intern Med 1987;2:183-7.

12 Balla JI, Rothert M, Greenbaum D, Black NA. Diagnostic cues in gastroenterology. Aust $N Z$ Z J Med 1983;13:469-77.
end

13 Tversky A, Kahneman D. Judgment under uncertainty: heuristics and biases. Tversky A, Kahneman D. Ju
Science 1974;185:1124-31.

14 Tversky A, Kahneman D. Availability: A heuristic for judging frequency and probability. In: Kahneman D, Slovic P, Tversky A, eds. Fudgment under uncertainty: heuristics and biases. Cambridge: Cambridge University Press, 1972:163.

15 Balla JI, Elstein AS, Gates P. Effects of prevalence and test diagnosticity upon clinical judgment of probability. Methods Inf Med 1983;22:25-8.

16 Balla JI. The use of critical cues and prior probability in decision making. Methods Inf Med 1982;21:9-14.

17 Tversky A, Kahneman D. The framing of decisions and the psychology of choice. Science 1981;211:453-8.

$18 \mathrm{McNeil}$ BJ, Pauker SG, Sox HC, Tversky A. On the elicitation of preferences for alternative therapies. $N$ Engl f Med 1982;306:1259-62.

19 Balla JI. The diagnostic process: a model for clinical teachers. Cambridge: Cambridge University Press, 1985.

20 Dowie J, Elstein AS. Professional judgment: a reader in clinical decision making. New York: Cambridge University Press, 1988.

21 Allman RM, Steinberg EP, Keruly JC, Dans PE. Physician tolerance for uncertainty. Use of liver-spleen scans to detect metastases. $7 \mathrm{Am} \mathrm{Med} \mathrm{Ass}$ 1985;254:246-9.

22 Elstein AS. Cognitive processes in clinical inference and decision making. In Turk DC, Salovey P, eds. Reasoning, inference and judgment in clinical psychology. New York: Free Press, Macmillan, 1988.

23 Kahneman D, Tversky A. Prospect theory: an analysis of decision under risk. Econometrica 1979;47:263-91.

24 Curley SP, Eraker SA, Yates JF. An investigation of patients' reactions to therapeutic uncertainty. Medical decision making 1984;4:501-11.

25 Curley SP, Young MJ, Yates JF. Characterizing physicians' perceptions of ambiguity. Medical Decision Making (in press).

26 Einhorn HJ, Hogarth RM. Decision making under ambiguity. Journal of Business 1986;59:S225-50.

\section{ANY QUESTIONS}

Does royal jelly from beehives have any unusual nutritional or healing properties?

Royal jelly has some important properties for the nutritional development of the immature bee larva, providing specific nutritional requirements and influencing maturation and the course of development in ways that are only partly understood. Royal jelly contains a group of biological active insect hormones. These are known to influence nucleic acid metabolism and are essential for the development of the queen bee. The jelly is also a rich source of vitamins. These special properties for the bee larva have led several people to claim that they are operational and valuable for humans. There is virtually no evidence or reason to suppose that the components have specific and desirable properties for man. Furthermore, the amount of royal jelly in most preparations is such that the dose recommended is too low to make an appreciable nutritional contribution to a human. '-D A T SOUTHGATE, head, nutrition and food quality research, Norwich

1 Bender AE. Health or hoax. London: Sphere, 1986:77.

When immunising a baby born prematurely should the doctor calculate the time for immunisation from the infant's real or expected birth date?

Many components of the immune system of the neonate are immature and do not attain adult levels of functioning for many months or even years. Premature infants are even less immunocompetent. Among other differences they have reduced concentrations of immunoglobulins and complement. The evidence suggests, however, that subsequent development of the immune system depends partly on antigen exposure rather than postconceptional age and despite these differences substantial data show that premature infants may be immunised effectively without allowing for their prematurity.

Smolen et al showed that preterm infants immunised with oral polio vaccine at 2 and 4 months responded as well as full term infants of the same age.' Premature infants given BCG at 5 days of age had as good a rate of tuberculin conversion as a similar group of infants immunised on their expected date of delivery. ${ }^{2}$ Bernbaum et al immunised a group of infants with gestations varying from 28 to 34 weeks against diphtheria, tetanus, and pertussis at 8,16 , and 24 weeks after birth. ${ }^{3}$ The antibody responses after the second and third doses were as good as those in full term infants immunised at the same ages. Interestingly, the preterm infants had a lower incidence of minor side effects such as bchavioural changes and local reactions with $15 \%$ receiving antipyretics as opposed to $54 \%$ in the full term group. A more recent study has confirmed these findings. ${ }^{+}$

Preterm infants may be safely and effectively immunised with the routine schedules based on their actual rather than corrected age. If infants are still in the hospital neonatal unit at 3 months their immunisation should be initiated by the hospital. - DAVID ELLIMAN, lecturer in community child health, London

1 Smolen P, Bland R, Heiligenstein E, et al. Antibody response to oral polio vaccine in premature infants. F Pediatr 1983;103:917-9.

Dawodu AH. Tuberculin conversion following BCG vaccination in preterm infants. Acta Paediatr Scand 1985;74:564-7.

3 Bernbaum JC, Daft A, Anolik R, et al. Response of preterm infants to diphtheria-tetanuspertussis immunisations. I Pediatr 1985;107:184-8.

4 Conway SP, James SR, Smithells RW, Melville-Smith N, Magrath D. Immunisation of the preterm baby. Lancet 1987;ii: 1326. 